\title{
Plasmablastic lymphoma: current perspectives
}

This article was published in the following Dove Press journal: Blood and Lymphatic Cancer:Targets and Therapy

\section{Andres Lopez' \\ Pau Abrisqueta ${ }^{2}$ \\ 'Lymphoma Unit, Department of Hematology, Vall d'Hebron University Hospital, Barcelona, Spain; ${ }^{2}$ Department of Hematology, Vall d'Hebron Institute of Oncology, Vall d'Hebron University Hospital, Barcelona, Spain}

Correspondence: Andres Lopez Hospital Universitari Vall d'Hebron, Pg. Vall d'Hebron, I 19-I29, 08035 Barcelona, Spain

Email andlopez@vhebron.net

\begin{abstract}
Plasmablastic lymphoma $(\mathrm{PbL})$ is a rare and aggressive B-cell malignancy with large neoplastic cells, most of them resembling plasmablasts that have a CD20-negative phenotype. Although initially described as being associated with HIV, over the years it has also been identified in patients with solid organ transplant and immunocompetent patients. Little is known about molecular basis that drives $\mathrm{PbL}$, and still its diagnosis remains challenging given its rarity. However, proper recognition of its clinical characteristics, localization, and morphological features can establish a correct diagnosis of $\mathrm{PbL}$ within the spectrum of $\mathrm{CD} 20$ negative large B-cell lymphomas (LBCLs). PbL is characterized by CD20 and PAX5 negativity together with the expression of CD38, CD138, MUM1/IRF4, Blimp1, and XBP1 plasmacytic differentiation markers. It is usually associated with Epstein-Barr virus infections, and MYC gene rearrangements. $\mathrm{PbL}$ should be carefully differentiated from other $\mathrm{CD} 20$-negative B-cell neoplasms, ie, primary effusion lymphoma, anaplastic lymphoma kinase-positive (ALK) large B-cell lymphoma, and LBCL in human herpesvirus 8-associated multicentric Castleman disease. Despite our improved understanding of this disease, its prognosis remains dismal with short overall survival. There is no standard of care for this entity. Several chemotherapy combinations have been used with hardly any differences on its outcome. Thus, new approaches with the addition of novel molecules are needed to overcome its poor prognosis. Our current understanding and knowledge of $\mathrm{PbL}$ relies primarily on case reports and small case series. In this review, we revise through an extensive literature search, the clinical and biological characteristics of this entity, and the potential therapeutic options.
\end{abstract}

Keywords: plasmablastic lymphoma, review

\section{Introduction}

Plasmablastic lymphoma $(\mathrm{PbL})$ is an aggressive B-cell malignancy highly associated with HIV. ${ }^{1}$ A fraction of large B-cell lymphomas (LBCL) share a plasmablastic differentiation with an aggressive behavior, refractoriness to chemotherapy, and poor prognosis in most cases. ${ }^{2}$ They are characterized by a gradual expression of transcription factors associated with the plasmacytic differentiation, CD38, CD138, MUM1, Blimp1, and XBP1, with decreased expression of CD20 and PAX5. ${ }^{3}$ In addition to PbL, plasmablastic/plasmacytic differentiation is well-documented in other entities such as primary effusion lymphoma, LBCL in human herpesvirus 8 (HHV-8)-associated multicentric Castleman disease, and anaplastic lymphoma kinase-positive LBCL. These constitute a subgroup of lymphomas with heterogeneous clinical, histological, and genetic features posing diagnostic challenges to pathologists. ${ }^{4} \mathrm{PbL}$ is the most common and well-described subtype. Nevertheless, this entity is extremely rare, and its clinicopathological features and optimal treatment strategies remain obscure. ${ }^{5}$ 


\section{Pathogenesis and biological features}

$\mathrm{PbL}$ was first described in 1997 by Delecluse et $\mathrm{al}^{6}$ in patients with HIV. It has later been reported in patients with solid organ transplantation, other immunosuppressed, and even immunocompetent patients. $^{7}$

$\mathrm{PbL}$ cells show immunoblastic morphology and immunophenotype with plasmacytic differentiation markers including positivity for CD38, CD138, MUM1, Blimp1, and XBP1, and MYC, with variable expression for CD45, CD79a, EMA, and $\mathrm{CD} 30$. Although it generally shows no expression of B-cell markers (CD20 and PAX5), CD20 can be weakly positive in about $10 \%$ of the cases. ${ }^{1,4}$ The cell of origin of the $\mathrm{PbL}$ is thought to be the plasmablast, an activated B lymphocyte that has gone through the process of somatic hypermutation and class-switching recombination. ${ }^{1}$

The biological bases of $\mathrm{PbL}$ are not yet completely known. Different data suggest that there is a close relationship with immunodeficiency conditions in a large proportion of the cases. ${ }^{6,8-10}$ In this sense, there is a clear association with HIV infection, but also with other immunosuppressed status, such as in the context of solid organ transplant patients. Yet, the diagnosis of $\mathrm{PbL}$ cases in immunocompetent patients is also well-known, and patients usually are classified into three groups based on their immune status: HIV-positive patients, posttransplant patients, and immunocompetent patients. ${ }^{711,12}$ However, when analyzing the third group of immunocompetent patients in detail, a nonnegligible percentage of cases show relatively immunosuppressed conditions. A recent analysis by the Lysa Group of HIV-negative and nontransplanted cases showed, in 55 of 62 patients, the presence of factors associated with a certain degree of immunosuppression, such as autoimmune diseases or chronic systemic inflammatory diseases, history of previous neoplasms, or an age over 60 years that could be related to immunosenescence.$^{13}$ Interestingly, they reported four cases that developed a $\mathrm{PbL}$ on a local inflammation. Only $5 \%$ of the cases of the Lysa Group global series could not be associated with any state of immunosuppression. ${ }^{13} \mathrm{PbL}$ can develop in HIV-positive patients without a severe immunosuppression state. More than 50\% of the cases of $\mathrm{PbL}$ in patients with HIV, in this series, were diagnosed in patients who received combined antiretroviral therapy (cART) and had CD4 counts greater than 200 cells/ $\mu \mathrm{L} .{ }^{13}$ The prevalence of HIV-positive and HIV-negative cases is not well-defined and ranges from $63 \%$ in some case reviews to $44 \%$ in the case registry of the National Cancer Data Base, or $41 \%$ in the Lysa Group cohort. ${ }^{13,14}$

A very high percentage of $\mathrm{PbL}$ cases show an association with Epstein-Barr virus (EBV) infection. EBV-encoded small RNA expression has been described in $80 \%$ of the HIV-positive cases and $\sim 50 \%$ of the HIV-negative cases. This suggests an important role of EBV in the pathogenesis of PbL. ${ }^{12-15}$ However, there is a proportion of EBV-negative cases in the different series reported, and neither HIV status nor EBV seem to confer different patterns of gene expression in PbL. ${ }^{16}$

Beyond the association of $\mathrm{PbL}$ with immunosuppression and EBV infection, genetic studies have revealed frequent complex karyotypes. Several groups have found genetic alterations comprising the $M Y C$ oncogene that cause overexpression of the MYC protein. The most frequent alterations are translocations of $M Y C$ with IG (in $~ 50 \%$ of cases), together with amplifications of $M Y C .{ }^{17,18}$ Moreover, overexpression of MYC can also be detected by immunohistochemistry in a large proportion of cases, which suggests a central role of MYC in the pathogenesis of this lymphoma. ${ }^{11,19}$ Finally, recurrent mutations in PRDM1, a gene that encodes the Blimp1 protein, have recently been described in 8 of 16 cases analyzed. These mutations in PRDM1 could alter the regulation of different targets, including MYC, in these lymphomas. ${ }^{20}$ In fact, loss of Blimp1 protein expression has recently been found to be associated with MYC overexpression, and decreased expression of $\mathrm{p} 53$ tumor-suppressor molecules in ABC-like diffuse large B-cell lymphoma (DLBCL). ${ }^{21}$

\section{Clinical features, survival, and prognostic factors}

$\mathrm{PbL}$ is more predominant in males $(75 \%$ of the cases in the various analyzed series). At diagnosis, $\mathrm{PbL}$ commonly presents in extranodal regions, the most frequent being the oral cavity, the digestive tract, and the skin. Most patients present at an advanced stage (III or IV), with frequent bone marrow involvement and presence of B symptoms ( $40 \%$ of patients). However, there are differences in the clinical presentation of patients with different immunological status. Location of $\mathrm{PbL}$ in HIV-negative patients is more heterogeneous than in HIV-positive patients, and bone marrow involvement, as well as B symptoms are less frequent. Although lymph node involvement is less frequent at diagnosis, it has been described in up to $30 \%$ of posttransplant patients. ${ }^{6,8,9,11-13,22,23} \mathrm{PbL}$ can be diagnosed as the final event (transformation) of an indolent lymphoproliferative syndrome..$^{20}$ Cases after an acute lymphoblastic leukemia or DLBCL have also been described..$^{20,24}$

The median age at diagnosis is around 50 years. However, the age of presentation is lower in HIV-positive patients, with a median age of 40 years, than in non-HIV patients, where the median age is above 50 years. This reinforces the 
concept that age-related senescence can play a relevant role in a proportion of HIV-negative cases. . $^{7,12-20,22-25}$

The prognosis of patients with $\mathrm{PbL}$ is generally poor with a median overall survival (OS) of 6-19 months, and no clear differences between HIV-positive and HIV-negative patients. ${ }^{7,8,12-20,22-25}$ A review of 300 patients with $\mathrm{PbL}$ showed a median survival of 10 months in HIV-positive patients, 11 months in HIV-negative patients, and only 7 months in posttransplant patients. ${ }^{7}$ More recently, the Lysa series, which comprises the largest cohort of $\mathrm{PbL}$ reported so far, has shown better survival outcomes with a median OS of 32 months, greater than that reported before. ${ }^{13}$ A multivariate analysis of this cohort showed that good prognosis was positively associated with low International Prognostic Index (IPI) and achieving a complete response (CR). ${ }^{13}$ Although HIV status does not seem to determine differences in the prognosis and survival of patients, some studies have suggested that HIV-positive patients may have a better outcome compared to HIV-negative patients. ${ }^{13,25}$ This better survival could be explained, in part, by the immunological restoration with cART treatments and by the lower age of HIV-positive patients compared with the HIV-negative cases, which could be associated with more intensive chemotherapy treatments. Supporting the later hypothesis, a study of 481 patients with $\mathrm{PbL}$, from the National Cancer Data Base, showed no impact of HIV status on survival when the analysis was stratified by age. ${ }^{14}$

The prognostic impact of EBV status is not clear and varies depending on the series and subgroups of patients analyzed. Some studies have found no prognostic differences in HIV-positive patients, while other studies suggest that EBV-positive patients may have a better prognosis in HIV-negative patients. ${ }^{7,25,26}$

Beyond the HIV and EBV status, IPI is able to stratify patients into different prognostic groups, and is probably the most used prognostic index. ${ }^{15,26,27}$ More recently, rearrangements or gains of $M Y C$ has been associated with a worse outcome and shorter survival in patients with $\mathrm{PbL}$ compared with patients without MYC alterations. ${ }^{7,12,15,28}$

\section{Treatment}

The range of treatments delivered to $\mathrm{PbL}$ patients has been extensive, from local control with radiotherapy in patients with localized disease to a variety of chemotherapy combinations. ${ }^{29}$ Chemotherapy treatments have included CHOP (cyclophosphamide, doxorubicin, vincristine, and prednisone) or CHOP-like regimens, Hyper-CVAD-MA (hyperfractionated cyclophosphamide, vincristine, doxorubicin, dexamethasone, and high-dose methotrexate and cytarabibe), CODOX-M/IVAC (cyclophosphamide, vincristine, doxorubicin, high-dose methotrexate/ifosfamide, etoposide, and high-dose cytarabine), COMB (cyclophosphamide, Oncovin, methyl-CCNU, and bleomycin), and infusional EPOCH (etoposide, prednisone, vincristine, cyclophosphamide, and doxorubicin). ${ }^{17,30,31}$ Spontaneous regressions have been observed in HIV-infected patients after initiation of cART or highly active antiretroviral therapy. ${ }^{32,33}$

Patients with localized disease have a better prognosis, and in some circumstances are not subsidiary of aggressive treatments. In these cases, disease control has been achieved with radiotherapy or combining doxorubicin-based chemotherapy with radiation therapy. ${ }^{29,34}$ However, the experience with radiotherapy alone is limited.

For patients with disseminated disease, polychemotherapy achieves more than $50 \%$ of complete remissions (CRs), but $\sim 70 \%$ of patients die of progressive disease, with an eventfree survival of 22 months, and an OS of 32 months, being significantly longer in patients achieving a CR. ${ }^{13}$ To date, there are no standards of care defining the optimal therapeutic approach. $\mathrm{CHOP}$ has been the most common regimen used in $\mathrm{PbL}$; however, NCCN guidelines do not consider an adequate therapy, and recommend more intensive regimens such as Hyper-CVAD-MA, CODOX-M/IVAC, or EPOCH (infusional) therapy. ${ }^{35}$ About $38 \%$ of 5 -year progression-free survival (PFS) and a $40 \%$ of 5-year OS in patients with $\mathrm{PbL}, 40 \%$ received Hyper-CVAD-MA regimen. ${ }^{36}$ Although infusional $\mathrm{EPOCH}$ regimen has not proven to achieve better results in $\mathrm{PbL}$ patients than other regimens, its use is supported by the good results achieved in HIV-associated Non-Hodgkin's Lymphoma, and is becoming the treatment of choice in many institutions. ${ }^{37}$

One step further is the autologous stem cell transplantation (ASCT). No prospective randomized trials have been conducted in this setting due to the difficulty of carrying out this study in such a rare disease. A limited number of cases coming from short series have been reported in both HIV and immunocompetent patients with $\mathrm{PbL}$, in relapsed or refractory $(\mathrm{R} / \mathrm{R})$ patients as well as in first response after frontline treatment. In patients with HIV, the Italian Cooperative Group on AIDS and Tumors (GICAT) reported five cases in R/R patients, with two deaths (at 4 and 6 months after ASCT) and three patients in CR after 21-79 months. ${ }^{27,38}$ Moffitt Cancer Center presented the experience of two non-HIV patients with $\mathrm{PbL}$ in partial response (PR) that underwent an ASCT. One of them achieved a $\mathrm{CR}$, the other had a progressive disease, and both died at 12 and 6 months after ASCT. ${ }^{39}$ With regard to 
frontline ASCT in patients with $\mathrm{PbL}$ after a $\mathrm{CR}$ or $\mathrm{PR}$, there is a need to consolidate the response in patients with a poor prognosis after $\mathrm{R} / \mathrm{R}$ to the firstline therapy. ${ }^{13,15}$ An analysis of 5 patients with $\mathrm{PbL}$ who underwent an ASCT after CHOP regimen from a multicenter Phase II study of GIGAT group, with the addition of two more patients belonging to the same group, showed that four of them continue in CR after 13-83 months, and one died 4 months after this procedure. ${ }^{27,40}$ With a median follow-up of 19.5 months for the entire series, the 2-year PFS and OS were $73 \%$ and $76 \%$, respectively.

The literature on allogeneic stem cell transplantation (allo-SCT) in PbL is considerably more limited compared with ASCT. In 2009, Hamadani and Devine ${ }^{41}$ reported one patient with $\mathrm{PbL}$ in $\mathrm{CR} 2$ who underwent a reduced-intensity allogeneic stem cell transplantation (RIC-allo-SCT) from a matched unrelated donor, and was alive 2 years after transplantation. To date, allo-SCT in PbL has not shown great efficacy. ${ }^{42}$

\section{Treatment approaches beyond the standard chemotherapy}

Given the low efficacy of the standard therapy, and the poor outcome of these patients, there is a need to move toward new therapeutic strategies by incorporating new agents. We here review some options split into two categories: 1) previously used drugs in small trials; and 2) potential future directions (Figure 1).

\section{Drugs previously used in very short series Bortezomib}

Bortezomib is a proteasome inhibitor widely used for the treatment of multiple myeloma (MM). There are reports of its activity in lymphoma, mainly in non-Germinal center B-cell like DLBCL and mantle cell lymphoma. ${ }^{43,44}$ Bortezomib is the most reported new drug for $\mathrm{PbL}$. It has been used as single agent, as well as in combination with chemotherapy. In a short series, out of six patients treated with bortezomib alone, five achieved a PR - two as frontline therapy and three as a salvage treatment. ${ }^{45}$ Bortezomib has been used in combination with CHOP as frontline therapy in three HIV-associated $\mathrm{PbL}$ patients, all of them achieved a $\mathrm{CR}$, and two of them were alive 14 and 22 months after $\mathrm{V}-\mathrm{CHOP} .{ }^{46}$ However, the most frequently used chemotherapy regimen in combination with bortezomib has been infusional EPOCH. Castillo et al ${ }^{47}$ reported a series of three patients with complete resolution of disease measured by positron emission tomography scan and free of relapse at 12, 18, and 24 months. More recently, Dittus et $\mathrm{al}^{48}$ and Castillo et $\mathrm{al}^{49}$ have reported a series of 8 and 16 patients with a CR rate of $87.5 \%$ and $94 \%$, respectively. Two patients in the latter series received an ASCT as consolidation. Dittus et $\mathrm{al}^{48}$ report a 2 -year PFS and OS of $50 \%$, and Castillo et $\mathrm{al}^{49}$ a 5 -year OS of $63 \%$. In relapsed patients, bortezomib has been used in combination with THP-COP (pirarubicin, cyclophosphamide, vincristine, and prednisone),

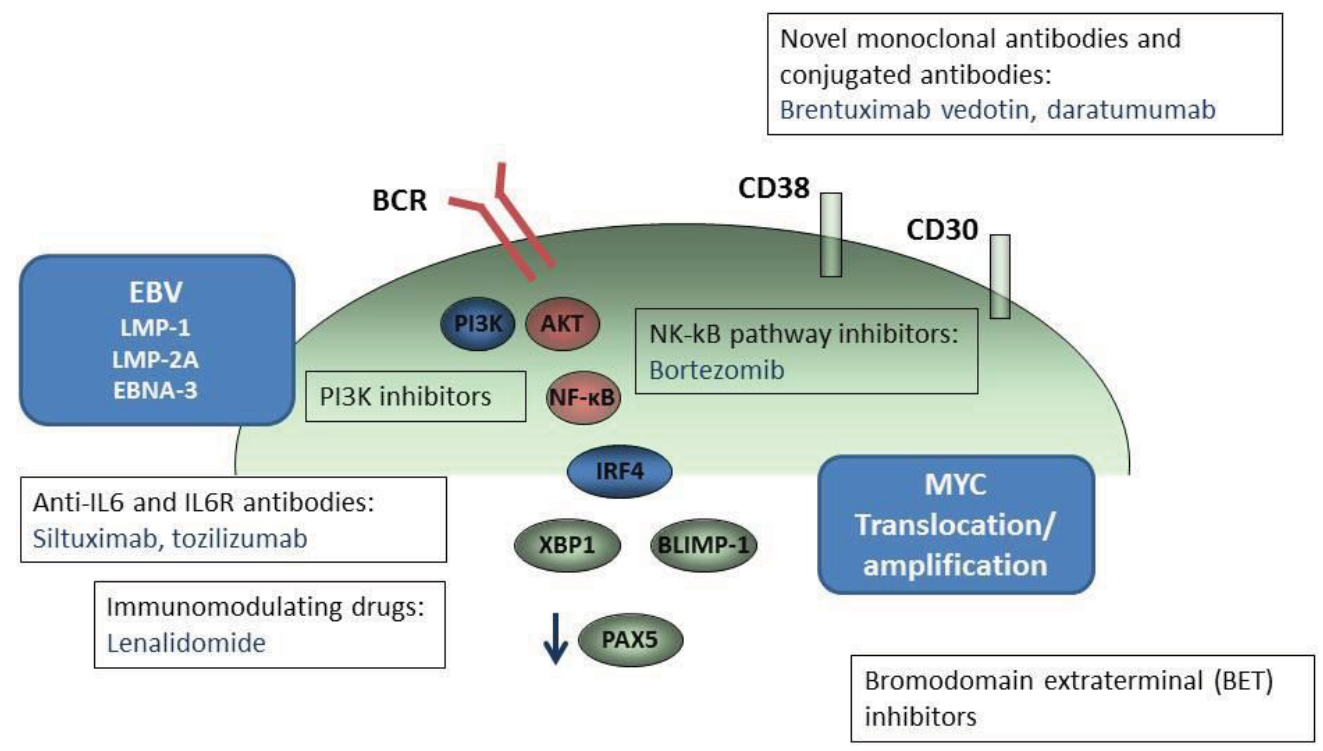

Plasmablast

Figure I New therapeutic targets in PbL.

Notes: Novel monoclonal antibodies and promising agents directed to inhibit different signaling pathways in PbL are represented.

Abbreviations: EBV, Epstein-Barr virus; PbL, plasmablastic lymphoma. 
ESHAP (etoposide, high-dose prednisolone, high-dose cytarabine, and platinum), ICE (Ifosfamide, carboplatin, and etoposide), bendamustine, rituximab, and DT-PACE with a CR rate of $16 \%$ and a PR rate of $84 \% .{ }^{45}$

\section{Lenalidomide}

The immunomodulatory agent lenalidomide is widely used in treating patients with $\mathrm{MM}$, and has also shown efficacy in non-GCB DLBCL. ${ }^{50}$ At present, there are two case reports showing a prompt but short response to single-agent lenalidomide in refractory $\mathrm{PbL}{ }^{51,52}$ Similarly, two cases were successfully treated with lenalidomide in combination with CHOP in one case, and with cyclophosphamide and dexamethasone in the other. ${ }^{53,54}$

\section{Brentuximab vedotin $(\mathrm{BrV})$}

CD30 expression is frequent in Hodgkin's lymphoma and anaplastic large cell lymphoma, but it is infrequently seen in DLBCL. BrV is an antibody-drug conjugate of antiCD30 that is well-established in the treatment of Hodgkin's lymphoma and anaplastic T-cell lymphoma. ${ }^{55,56}$ There are some data describing a variable expression of CD30 in $\mathrm{PbL}$, averaging $\sim 30 \%$ of the cases. ${ }^{20} \mathrm{~A}$ dramatic response to $\mathrm{BrV}$ has been reported in a single case, but the patient died shortly due to previous disease disabilities. ${ }^{57}$

\section{Anti-IL6 and IL6R antibodies (Siltuximab,Tozilizumab)}

As mentioned before, EBV has been detected frequently in $\mathrm{PbL} .{ }^{7}$ In cell lines derived from a patient with HIV-associated $\mathrm{PbL}$ harboring EBV (PBL-1), starvation of IL6 or addition of tozilizumab, an inhibitory antibody for the IL6 receptor, induced apoptosis in the PBL-1 cell line. This indicates an IL6 dependency of this cell line to proliferate and survive. ${ }^{58}$ Recently, a plasmablastic microlymphoma arising in HHV8-associated multicentric Castleman disease in an HIV-negative patient that did not express EBV proteins nor CD30, showed a clinical response to siltuximab, an anti-IL6 antibody. ${ }^{59}$

\section{Future directions}

Potential therapeutic approaches for patients with $\mathrm{PbL}$ could include EBV-directed therapies such as antiviral agents and EBV-targeted cellular immunotherapy, not yet evaluated in these patients. Many antiviral agents do not act due to the quiescent nature of the EBV outside the lytic phase. Arginine butyrate upregulates the thymidine kinase and induces lytic phase. A Phase I/II trial of arginine butyrate in refractory patients with EBV-associated lymphomas, in combination with ganciclovir, showed limited activity except for posttransplantation lymphoproliferative disorders, in which a response rate of $83 \%$ was observed. ${ }^{60} \mathrm{EBV}$-specific cytotoxic $\mathrm{T}$ lymphocytes have several limitations, such as a long preparation time and the need for specialized facilities for their production. ${ }^{61}$ Some of these drawbacks could be overcome by using autologous EBV-specific CAR T-cells with CD30 as target (NCT01192464) or CAR T-cells directed to other specific target.

Immunostains for programmed cell death-ligand 1 (PDL1) have showed a high or moderate expression in microenvironment cells of $\mathrm{PbL}$ ( $60 \%-72 \%$ of cells), and programmed death 1 (PD-1) in $22.5 \%$ of cases of PbL tumor cells. ${ }^{62}$ Both EBV-positive and EBV-negative $\mathrm{PbL}$ exhibited high expression of PD-1 and PDL-1. These findings constitute a strong rationale for testing anti-PD-1 or anti-PDL-1 monoclonal antibodies in this pathology.

MYC translocation has been found in more than $50 \%$ of patients with $\mathrm{PbL}$, mainly in HIV-infected patients. More frequently, MYC appears overexpressed. ${ }^{7,20}$ The $M Y C$ gene has been considered untargetable because of a lack of binding domain. ${ }^{63}$ Recently, a small selective molecule, bromodomain extraterminal (BET) inhibitor (JQ1) has shown to induce cell cycle arrest by inhibition of $M Y C$ transcription. ${ }^{64}$ Thus, BET inhibitors could be tested in some of these patients.

The PI3K/Akt/m-TOR signaling pathway is another major pathway of IL-6 signaling, which occurs downstream of IL-6R/gp130/Jak. Inhibition of the PI3K/Akt/m-TOR pathway may induce cell death in a plasmablastic cell line (PBL-1), which suggests that inhibitors of this type could be potential therapeutic agents for $\mathrm{PbL} .{ }^{58}$

Finally, daratumumab, an antibody directed against CD38, has shown an outstanding activity in patients with R/R MM. ${ }^{65,66} \mathrm{PbL}$ exhibits a strong expression of CD38, and could be an optimal target for the treatment of this disease. Although several cases have been treated with daratumumab as salvage therapy, there are still no reports of its efficacy. Our personal experience is limited to a case with $\mathrm{PbL}$ treated at our institution with daratumumab alone in third line. The patient experienced a dramatic response shortly followed by a rapid progression of the disease (unpublished). We assume that results can be improved in combination with other drugs or chemotherapy. In fact, in a patient treated with daratumumab in combination with ICE followed by an ASCT as salvage therapy, reportedly relapsed after V-EPOCH, achieving a CR that persisted at the time of publication, 15 months later. ${ }^{49}$ 


\section{Conclusion}

$\mathrm{PbL}$ is a rare and aggressive subtype of LBCL. Although the WHO recognizes it as most commonly occurring with HIV infection, it extends beyond patients with HIV, with a significant proportion of cases occurring in post-transplant and immunocompetent patients. It is frequently associated with EBV, and in more than $50 \%$ of cases shows MYC translocation or amplification. Awareness of this entity, as well as immunohistochemistry and correlation with clinical findings are crucial for establishing a correct diagnosis. Currently available chemotherapy fails to achieve good results, but prolonged remissions are possible. Clinical trials with novel immunotherapeutic agents and other drugs targeting some genes involved in the activation of NF- $\kappa \mathrm{B}$ pathways, some of which are already ongoing, may show promising results.

\section{Disclosure}

The authors report no conflicts of interest in this work.

\section{References}

1. Campo E, Stein H, Harris NL. Plasmablastic lymphoma. WHO Classification of Tumors of Hematopoietic and Lymphoid Tissues. Swerdlow SH, Campo E, Harris NL, editors. Lyon, France: IARC Press; 2017:321-322.

2. Harris NL, Jaffe ES, Diebold J, et al. World Health Organization classification of neoplastic diseases of the hematopoietic and lymphoid tissues: report of the Clinical Advisory Committee meeting-Airlie House, Virginia, November 1997. J Clin Oncol. 1999;17(12):3835-3849.

3. Li J, Zhao S, Wang J, Chen J, Wen W, Zhang Q. CD20-negative diffuse large B cell lymphoma: a comprehensive analysis of 695 cases. Tumour Biol. 2016;37(3):3619-3637.

4. Montes-Moreno S, Gonzalez-Medina AR, Rodriguez-Pinilla SM, et al. Aggressive large B-cell lymphoma with plasma cell differentiation: immunohistochemical characterization of plasmablastic lymphoma and diffuse large B-cell lymphoma with partial plasmablastic phenotype. Haematologica. 2010;95(8):1342-1349.

5. Montes-Moreno S, Montalbán C, Piris MA. Large B-cell lymphomas with plasmablastic differentiation: a biological and therapeutic challenge. Leuk Lymphoma. 2012;53(2):185-194.

6. Delecluse HJ, Anagnostopoulos I, Dallenbach F, et al. Plasmablastic lymphomas of the oral cavity: a new entity associated with the human immunodeficiency virus infection. Blood. 1997;89(4):1413-1420.

7. Morscio J, Dierickx D, Nijs J, et al. Clinicopathologic comparison of plasmablastic lymphoma in HIV-positive, immunocompetent, and posttransplant patients: single-center series of 25 cases and meta-analysis of 277 reported cases. Am J Surg Pathol. 2014;38(7):875-886.

8. Dong HY, Scadden DT, de Leval L, et al. Plasmablastic Lymphoma in HIV-Positive Patients. Am J Surg Pathol. 2005;29(12):1633-1641.

9. Song MK, Chung JS, Shin HJ, et al. Clinical significance of metabolic tumor volume by PET/CT in stages II and III of diffuse large B cell lymphoma without extranodal site involvement. Ann Hematol. 2012;91(5):697-703.

10. Teruya-Feldstein J, Chiao E, Filippa DA, et al. CD20-negative largecell lymphoma with plasmablastic features: a clinically heterogenous spectrum in both HIV-positive and -negative patients. Ann Oncol. 2004;15(11):1673-1679.

11. Loghavi S, Alayed K, Aladily TN, et al. Stage, age, and EBV status impact outcomes of plasmablastic lymphoma patients: a clinicopathologic analysis of 61 patients. J Hematol Oncol. 2015;8(1):65.
12. Castillo JJ, Bibas M, Miranda RN. The biology and treatment of plasmablastic lymphoma. Blood. 2015;125(15):2323-2330.

13. Tchernonog E, Faurie P, Coppo P, et al. Clinical characteristics and prognostic factors of plasmablastic lymphoma patients: analysis of 135 patients from the LYSA group. Ann Oncol. 2017;28(4):843-848.

14. Qunaj L, Castillo JJ, Olszewski AJ. Survival of patients with CD20negative variants of large B-cell lymphoma: an analysis of the National Cancer Data Base. Leuk Lymphoma. 2018;59(6):1-9.

15. Castillo JJ, Furman M, Beltrán BE, et al. Human immunodeficiency virus-associated plasmablastic lymphoma: poor prognosis in the era of highly active antiretroviral therapy. Cancer. 2012;118(21):5270-5277.

16. Chapman J, Gentles AJ, Sujoy V, et al. Gene expression analysis of plasmablastic lymphoma identifies downregulation of B-cell receptor signaling and additional unique transcriptional programs. Leukemia. 2015;29(11):2270-2273.

17. Valera A, Balagué O, Colomo L. IG/MYC rearrangements are the main cytogenetic alteration in plasmablastic lymphomas. Am J Surg Pathol. 2011;34(11):1686-1694.

18. Bogusz AM, Seegmiller AC, Garcia R, Shang P, Ashfaq R, Chen W. Plasmablastic lymphomas with $\mathrm{MYC} / \mathrm{IgH}$ rearrangement: report of three cases and review of the literature. Am J Clin Pathol. 2009;132(4):597-605.

19. Valera A, Colomo L, Martínez A, et al. ALK-positive large B-cell lymphomas express a terminal B-cell differentiation program and activated STAT3 but lack MYC rearrangements. Mod Pathol. 2013;26(10): 1329-1337.

20. Montes-Moreno S, Martinez-Magunacelaya N, Zecchini-Barrese T, et al. Plasmablastic lymphoma phenotype is determined by genetic alterations in MYC and PRDM1. Mod Pathol. 2017;30(1):85-94.

21. Xia Y, Xu-Monette ZY, Tzankov A, et al. Loss of PRDM1/BLIMP-1 function contributes to poor prognosis of activated B-cell-like diffuse large B-cell lymphoma. Leukemia. 2017;31(3):625-636.

22. Colomo L, Loong F, Rives S, et al. Diffuse large B-cell lymphomas with plasmablastic differentiation represent a heterogeneous group of disease entities. Am J Surg Pathol. 2004;28(6):736-747.

23. Harmon CM, Smith LB. Plasmablastic lymphoma a review of clinicopathologic features and differential diagnosis. Arch Pathol Lab Med. 2016;140(10):1074-1078.

24. Marini C, Baldaia H, Trigo F, Castillo JJ. Transformation of a previously diagnosed diffuse large B-cell lymphoma to plasmablastic lymphoma. Am J Hematol. 2016;91(8):E324.

25. Castillo JJ, Winer ES, Stachurski D, et al. Clinical and pathological differences between human immunodeficiency virus-positive and human immunodeficiency virus-negative patients with plasmablastic lymphoma. Leuk Lymphoma. 2010;51(11):2047-2053.

26. Schommers P, Wyen C, Hentrich M, et al. Poor outcome of HIV-infected patients with plasmablastic lymphoma: results from the German AIDSrelated lymphoma cohort study. AIDS. 2013;27(5):842-845.

27. Cattaneo C, Re A, Ungari M, et al. Plasmablastic lymphoma among human immunodeficiency virus-positive patients: results of a single center's experience. Leuk Lymphoma. 2015;56(1):267-269.

28. Schommers P, Wyen C, Hentrich M, et al. Poor outcome of HIV-infected patients with plasmablastic lymphoma: results from the German AIDSrelated lymphoma cohort study. AIDS. 2013;27(5):842-845.

29. Phipps C, Yeoh KW, Lee YS, et al. Durable remission is achievable with localized treatment and reduction of immunosuppression in limited stage EBV-related plasmablastic lymphoma. Ann Hematol. 2017;96(11):1959-1960.

30. Zelenetz AD, Abramson JS, Advani RH, et al. Non-Hodgkin's Lymphomas. J Natl Compr Canc Netw. 2010;8(3):288-334.

31. Koizumi Y, Uehira T, Ota Y, et al. Clinical and pathological aspects of human immunodeficiency virus-associated plasmablastic lymphoma: analysis of 24 cases. Int $J$ Hematol. 2016;104(6):669-681.

32. Armstrong R, Bradrick J, Liu YC. Spontaneous regression of an HIVassociated plasmablastic lymphoma in the oral cavity: a case report. $J$ Oral Maxillofac Surg. 2007;65(7):1361-1364. 
33. Nasta SD, Carrum GM, Shahab I, Hanania NA, Udden MM. Regression of a plasmablastic lymphoma in a patient with HIV on highly active antiretroviral therapy. Leuk Lymphoma. 2002;43(2):423-426.

34. Pinnix CC, Shah JJ, Chuang H, et al. Doxorubicin-based chemotherapy and radiation therapy produces favorable outcomes in limited-stage plasmablastic lymphoma: a single-institution review. Clin Lymphoma Myeloma Leuk. 2016;16(3):122-128.

35. Zelenetz AD, Gordon LI, Wierda WG, Abramson JS, Advani RH, Andreadis C. B-cell lymphomas. NCCN Clin Pract Guidel Oncol. Vol. Version 1; 2017.

36. Patel K, Feng L, Oki Y, et al. Plasmablastic lymphoma: 28 patient single institution experience. Blood. 2013;122(21):4310 LP-4310.

37. Sparano JA, Lee JY, Kaplan LD, et al. Rituximab plus concurrent infusional EPOCH chemotherapy is highly effective in HIV-associated B-cell non-Hodgkin lymphoma. Blood. 2010;115(15):3008-3016.

38. Re A, Cattaneo C, Michieli M, et al. High-dose therapy and autologous peripheral-blood stem-cell transplantation as salvage treatment for HIVassociated lymphoma in patients receiving highly active antiretroviral therapy. J Clin Oncol. 2003;21(23):4423-4428.

39. Liu M, Liu B, Liu B, et al. Human immunodeficiency virus-negative plasmablastic lymphoma: a comprehensive analysis of 114 cases. Oncol Rep. 2015;33(4):1615-1620.

40. Re A, Michieli M, Casari S, et al. High-dose therapy and autologous peripheral blood stem cell transplantation as salvage treatment for AIDS-related lymphoma: long-term results of the Italian Cooperative Group on AIDS and Tumors (GICAT) study with analysis of prognostic factors. Blood. 2009;114(7):1306-1313.

41. Hamadani M, Devine SM. Reduced-intensity conditioning allogeneic stem cell transplantation in HIV patients with hematologic malignancies: yes, we can. Blood. 2009;114(12):2564-2566.

42. Al-Malki MM, Castillo JJ, Sloan JM, Re A. Hematopoietic cell transplantation for plasmablastic lymphoma: a review. Biol Blood Marrow Transplant. 2014;20(12):1877-1884.

43. Leonard JP, Kolibaba K, Reeves JA, et al. Randomized phase 2 openlabel study of R-CHOP \pm bortezomib in patients (Pts) with untreated non-germinal center B-cell-like (Non-GCB) subtype diffuse large cell lymphoma (DLBCL): results from the Pyramid trial (NCT00931918). Blood. 2015;126(23):811.

44. Robak T, Huang H, Jin J, et al. Bortezomib-based therapy for newly diagnosed mantle-cell lymphoma. N Engl J Med. 2015;372(10):944-953.

45. Guerrero-Garcia TA, Mogollon RJ, Castillo JJ. Bortezomib in plasmablastic lymphoma: a glimpse of hope for a hard-to-treat disease. Leuk Res. 2017;62(September):12-16.

46. Fernandez-Alvarez R, Gonzalez-Rodriguez AP, Rubio-Castro A, et al. Bortezomib plus CHOP for the treatment of HIV-associated plasmablastic lymphoma: clinical experience in three patients. Leuk Lymphoma. 2016;57(2):463-466.

47. Castillo JJ, Reagan JL, Sikov WM, Winer ES. Bortezomib in combination with infusional dose-adjusted EPOCH for the treatment of plasmablastic lymphoma. Br J Haematol. 2015;169(3):352-355.

48. Dittus C, Grover N, Ellsworth S, Tan X, Park SI. Bortezomib in combination with dose-adjusted EPOCH (etoposide, prednisone, vincristine, cyclophosphamide, and doxorubicin) induces long-term survival in patients with plasmablastic lymphoma: a retrospective analysis. Leuk Lymphoma. 2018;59(9):2121-2127.

49. Castillo JJ, Guerrero-Garcia T, Baldini F, et al. Bortezomib plus EPOCH is effective as frontline treatment in patients with plasmablastic lymphoma. Br J Haematol. 2018:1-3.
50. Fang C, Zhu D, Dong H, et al. Lenalidomide alone or in combination with chemotherapy treatment for subtypes of diffuse large B cell lymphoma: a systematic review and meta-analysis. Int $J$ Clin Exp Med. 2015;8(7):10705-10713.

51. Carras S, Regny C, Peoc'h M, et al. Dramatic efficacy of low dose lenalidomide as single agent in a patient with refractory gastric nonhuman immunodeficiency virus-associated plasmablastic lymphoma. Leuk Lymphoma. 2015;56(10):2986-2988.

52. Bibas M, Grisetti S, Alba L. Patient with HIV-associated plasmablastic lymphoma responding to bortezomib alone and in combination with dexamethasone, gemcitabine, oxaliplatin, cytarabine, and pegfilgrastim chemotherapy and lenalidomide alone. J Clin Oncol. 2012;30(31):2012-2014.

53. Yanamandra U, Sahu KK, Jain N, Prakash G, Saikia U, Malhotra P. Plasmablastic lymphoma: successful management with CHOP and lenalidomide in resource constraint settings. Ann Hematol. 2016;95(10): 1715-1717.

54. Schmit JM, Delaune J, Norkin M, Grosbach A. A case of plasmablastic lymphoma achieving complete response and durable remission after lenalidomide-based therapy. Oncol Res Treat. 2017;40(1-2):46-48.

55. Younes A, Bartlett NL, Leonard JP, et al. Brentuximab vedotin (SGN-35) for relapsed CD30-positive lymphomas. $N$ Engl J Med. 2010;363(19): 1812-1821.

56. Forero-Torres A, Fanale M, Advani R, et al. Brentuximab vedotin in transplant-naive patients with relapsed or refractory Hodgkin lymphoma: analysis of two phase I studies. Oncologist. 2012;17(8):1073-1080.

57. Pretscher D, Kalisch A, Wilhelm M, Birkmann J. Refractory plasmablastic lymphoma-a review of treatment options beyond standard therapy. Ann Hematol. 2017;96(6):967-970.

58. Mine S, Hishima T, Suganuma A, et al. Interleukin-6-dependent growth in a newly established plasmablastic lymphoma cell line and its therapeutic targets. Sci Rep. 2017;7(1):1-11.

59. Koenig G, Stevens TM, Peker D. Plasmablastic microlymphoma arising in human herpesvirus-8-associated multicentric Castleman disease in a human immunodeficiency virus-seronegative patient with clinical response to anti-interleukin-6 therapy. Histopathology. 2015;67(6):930-932.

60. Perrine SP, Hermine O, Small T, et al. A phase $1 / 2$ trial of arginine butyrate and ganciclovir in patients with Epstein-Barr virus-associated lymphoid malignancies. Blood. 2007;109(6):2571-2578.

61. Castillo JJ, Reagan JL, Bishop KD, Apor E. Viral lymphomagenesis: from pathophysiology to the rationale for novel therapies. $\mathrm{Br} \mathrm{J} \mathrm{Hae-}$ matol. 2014;165(3):300-315.

62. Laurent C, Fabiani B, do C, et al. Immune-checkpoint expression in Epstein-Barr virus positive and negative plasmablastic lymphoma: a clinical and pathological study in 82 patients. Haematologica. 2016;101(8):976-984.

63. Darnell JE. Transcription factors as targets for cancer therapy. Nat Rev Cancer. 2002;2(10):740-749.

64. Delmore JE, Issa GC, Lemieux ME, et al. BET bromodomain inhibition as a therapeutic strategy to target c-Myc. Cell. 2011;146(6):904-917.

65. Palumbo A, Chanan-Khan A, Weisel K, et al. Daratumumab, bortezomib, and dexamethasone for multiple myeloma. NEngl J Med. 2016;375(8): 754-766.

66. Dimopoulos MA, Oriol A, Nahi H, et al. Daratumumab, lenalidomide, and dexamethasone for multiple myeloma. NEngl J Med. 2016;375(14): 1319-1331. 


\section{Publish your work in this journal}

Blood and Lymphatic Cancer: Targets and Therapy is an international, peer-reviewed, open access journal focusing on blood and lymphatic cancer research, identification of therapeutic targets and the optimal use of preventative and integrated treatment interventions to achieve improved outcomes, enhanced survival and quality of life for the cancer patient. The manuscript management system is completely online and includes a very quick and fair peer-review system. Visit http://www.dovepress.com/testimonials.php to read real quotes from published authors.

Submit your manuscript here: https://www.dovepress.com/blood-and-lymphatic-cancer-targets-and-therapy-journal 